\title{
Are You Smarter Than a Fifth Grader?
}

David A. Tyckoson, 2007-2008

President of the Reference and User Services Association, is Head of Public Services, Henry Madden Library, California State University, Fresno; e-mail: davety@csufresno.edu

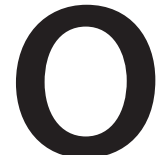

$f$ course you are. If you are reading this column, you are most likely a college-educated, twenty-first-century information professional who is engaged in assisting members of your community navigate through, find, and understand complex information resources. This takes skills far beyond those of a fifth-grade education. So why am I asking?

At the time of the writing of this column, a new television game show was rising in popularity. For those of you who stay out of touch with current popular culture or who may be reading this in future years long after this particular show has been cancelled, it is based upon an interesting premise. Hosted by Jeff Foxworthy (who despite his blue collar, redneck humor is a graduate of Georgia Tech and was formerly employed by IBM), adults compete against a team of fifth-grade students to answer factual questions compiled from grade school textbooks. Questions are rated in difficulty from the first through fifth grade. Topics are grouped in categories ranging in supposedly increasing levels of difficulty, from first-grade science to third-grade spelling to fifth-grade geometry. Answering all of the questions correctly results in a reward of $\$ 1,000,000$, whereas failing to complete that task requires the adult to say: "I am not smarter than a fifth grader." Needless to say, the producer's money at the Fox network is pretty safe, and most adults end up admitting their ignorance.

Admittedly, the show picks some pretty smart fifth graders to compete against the adults. The children answer the questions correctly much more frequently than the adults do, and there is obvious joy when they get the answers right. In fact, at least one member of the current cast has already demonstrated the potential to become a future RUSA member. The children's desire to show off their intelligence by matching wits with adults is refreshing, demonstrating to other young people that learning is not only cool, but that it can literally pay off with some big money. The fact that the adults can "cheat" off the kids lends an extra air of respect to the children, although it also sends the negative message that cheating on tests is acceptable behavior. Overall, the program takes knowledge of basic facts and turns it into some pretty good entertainment

As a reference librarian, this program has caught my attention for a number of reasons. The idea that adults who have presumably completed their $\mathrm{K}-12$ schooling cannot beat a group of fifth graders on a quiz show says something about our society. The fact that we-that I-actually watch such programming probably says even more. And the fact that most adults fail to correctly answer all of the questions says 
something about how we measure the success and failure of information queries.

The entire success of this show depends on measuring intelligence through correct or incorrect answers to factual questions. Although the nature of the questions is a little different, the process sounds a lot like the popular image of reference service. As with Katherine Hepburn in the 1950s film Desk Set, people come to the library with questions and librarians find answers. As in that film, some questions might be easy, such as finding the names of Santa's reindeer. Some are more difficult, such as determining whether the King of the Watusis drives an automobile (and, if so, what make and model). In this version of reference service, the librarian serves as the definitive, correct arbitrator of factual information. This is very often the popular image of the reference librarian. However, it is not the reality.

With the development of the Internet and such Web tools as Yahoo! and Google, people are able to find accurate factual information on their own. While reference librarians were never primarily fact givers, the fact that that information was published in sources not immediately available to the user gave the illusion that this was our primary function. With today's fast, free, and universal access to information, users are able to conduct that type of research on their own. As a result, reference librarians have moved further and further away from the fact business, and deeper and deeper into the research consultation business. Instead of finding specific answers to factual questions, reference librarians suggest research strategies and recommend potential information resources.

As the ease of finding factual information has increased, our reference statistics have decreased. Measuring success by the numbers of questions answered might have made us look good when we answered lots of easy questions, but those indicators are failing us now that we spend almost all of our time on difficult research queries. Talking to reference librarians around the nation, I always hear the same response - the statistics are down, but we are busier than ever. For many, this creates an odd disconnect between what they are actually doing as a reference librarian and what others perceive that they are doing. As we move further and further away from the role of the walking encyclopedia, and closer and closer toward the role of the information counselor, we need to develop new ways to assess the impact of reference services on libraries and the communities that they serve.

As president of RUSA, I am very interested in redefining reference service. What exactly does reference service mean at the beginning of the twenty-first century? How should we measure what we do, and, more importantly, how can we positively convey what we do to the rest of the world? What is quality service, and how can we improve upon that quality? These issues will be the themes of my presidential year and of the 2008 RUSA President's Program. At least one RUSA committee is already tackling this topic and working on a redefinition of reference services. Many others also are involved in a variety of tasks related to this topic. If you have ideas or want to get involved, feel free to contact me. This is not my personal initiative, but RUSA's.

This brings me back to "Are You Smarter Than a Fifth Grader?" The show glamorizes the ability to regurgitate factual information. It equates being smart with knowing facts. While it is fun to watch, it is becoming more and more removed from what we do as reference librarians. Most questions that we get asked do not have simple, factual answers, and many have no answers at all. Being smart is not about knowing the facts, but knowing the pathways to resources regarding complex problems.

As I watch the show, I often realize that I do not know the answer to the question, but I certainly do know where I would go to look it up. If this show really catches on and becomes a success, RUSA should sponsor the sequel: "Are You Smarter Than a Reference Librarian?" Instead of competing against children, contestants would play against reference departments from major public and academic libraries. Instead of answering factual questions, contestants would have to figure out what information resources to use, develop a search strategy, and analyze the results. However, it wouldn't be very entertaining. Nobody will ever be smarter than a roomful of reference librarians. 